\title{
Aplicação atual do Princípio da Precaução nos TRIBUNAIS INTERNACIONAIS
}

\section{Marcos Homrich Hickmann}

\section{INTRODUÇÃO}

A julgar pelas convenções internacionais existentes em matéria ambiental, muito estaria sendo feito nesse âmbito para evitarem-se impactos negativos sobre o ambiente $\mathrm{e}$ para minimizar ou reparar os que eventualmente cheguem a ocorrer. Não bastassem os acordos internacionais diretamente voltados à proteção ambiental e à reparação de danos, muitos tratados cujo objetivo principal é outro também incluem uma referência em algum artigo ou considerando a respeito da consciência dos Estados-Partes acerca dos problemas ambientais e do seu desejo de contribuir para evitá-los.

Uma atitude que tem sido reiteradamente prevista é a precaução. É verdade que, nas primeiras convenções internacionais em matéria ambiental, ela surgia de forma rarefeita, pouco objetiva ${ }^{1}$. Já em desenvolvimentos mais recentes do direito internacional ambiental, ela tem sido mencionada como "princípio", e seu conteúdo tem sido mais objetivamente definido, embora ainda com algumas imprecisões².

Na verdade, essas imprecisões relativas são até importantes, pois permitem que a jurisprudência internacional molde a precaução à vista de elementos concretos, ao invés de se cristalizar um conceito pensado em abstrato, que poderia restar ineficaz. Justamente, este trabalho visa a identificar o tratamento atual do princípio da precaução nos tribunais internacionais, pois é sua aplicação prática, e não sua simples menção num tratado internacional que conta para a proteção do meio ambiente. Foram selecionados, então, alguns casos recentes apreciados pela Corte Internacional de Justiça, pelo Órgão de Solução de Disputas da Organização Mundial do Comércio, pelo Tribunal Internacional para o Direito do Mar e pelos tribunais arbitrais ad boc do Mercosul.

1 Exemplo é o "princípio" 2 da Declaração de Estocolmo de 1972.

2 Ver, por exempla, o Pröncípio 15 da Declaração do Rio de 1992. Nota-se, pois, a presença de expressões que devem ser precisadas num momento posterior, como "dentro de suas possibilidades", "impacto significativo" etc. 


\section{APLICAÇÃO DO PRINCÍPIO DA PRECAUÇÃO NOS TRIBUNAIS INTERNACIONAIS}

\subsection{Corte Internacional de Justiça}

Tomaremos, aqui, como exemplo do approach da Corte Internacional de Justiça ao princípio da precaução, o caso do diferendo entre a Hungria e a Eslováquia (acórdão de 25.09.1997) emergente de um tratado entre esses dois Estados de 1977, relativo ao aproveitamento do Rio Danúbio, que lhes serve de fronteira por alguma extensão.

Em 16 de setembro de 1977, a República Popular Húngara e a República Socialista Tchecoslovaca firmaram um tratado relativo à construção e ao funcionamento do sistema de eclusas de Gabcíkovo-Nagymaros, instrumento que entrou em vigor em 30 de junho do ano seguinte. Destinava-se à valorização e à exploração dos recursos naturais da região entre Bratislava (na Tchecoslováquia) e Budapest (na Hungria), especialmente aqueles recursos hídricos (bacia do Danúbio), para energia, transporte e agricultura. Para tanto, previa-se a construção, como investimento conjunto, de um sistema de barragem e eclusas ao longo dos aproximadamente 200 quilômetros de extensão dessa parte do Danúbio. Os principais objetivos eram a geração de hidreletricidade, o melhoramento da navegabilidade naquele trecho e a proteção das regiões ribeirinhas contra inundações. Além disso, as partes colocariam o tratado em práticade maneira que não se comprometesse a qualidade das águas do rio.

Um acordo de assistência mútua de 16.09.1977 fixava o calendário para a execução das obras e modificava em parte a repartição dos trabalhos do tratado original. Os trabalhos começaram em 1978. Por iniciativa da Hungria, as partes acordaram, por dois protocolos firmados em 10.10.1983, atrasar os trabalhos e postergat o início da operação das centrais em quatro anos. Mais tarde, um protocolo de 06.02.1989 emendando o acordo de assistência mútua aceleraria o projeto novamente, em quinze meses, devendo o conjunto estar funcionando em 1994.

Entretanto, em função de pesadas críticas suscitadas na Hungria, o governo deste país, em 13.05.1989, suspendeu os trabalhos em Nagymaros até a conclusão de diversos estudos que as autoridades conduziriam até 31.07.1989, prazo estendido, em 21.07.1989, para 31.10.1989. Ao mesmo tempo (21.07), suspenderam-se os trabalhos em Dunakiliti também. Finalmente, em 27.10.1989, a Hungria decidiu abandonar as obras em Nagymaros e manter o "statu quo" em Dunakiliti.

Nesse período, as partes travaram negociações. A Tchecoslováquia também empreendeu estudos que originaram possibilidades de soluções alternativas. A que ficou conhecida como "variante C" implicava entre outros, o desvio unilateral do Danúbio pela Tchecoslováquia no seu território, uns $10 \mathrm{~km}$ antes de Dunakiliti, a construção de uma barragem a Cunovo, uma eclusa de navegação auxiliar $\epsilon$ duas hidrelétricas (uma no afluente Moson, outro no leito original do Danúbio). 
Em 23.07.1991, o governo Eslovaco decidiu começar em setembro do mesmo ano as obras para pôt em funcionamento o projeto de Gacíkovo graças à solução provisória ("variante C"), decisão ratificada pelo governo federal tchecoslovaco em 25 de julho. Os trabalhos da variante $\mathrm{C}$ começaram em novembro. As negociações entre Hungria e Eslováquia desenrolaram-se sem acordo. Em 19.05.1992, a Hungria comunicou ao governo tchecoslovaco, a contar de 25.05.1992, a terminação do tratado de 1977. Em 15.10.1992, a Tchecoslováquia iniciou os trabalhos para o fechamento do Danúbio e, desde 23.10.1992, procedeu à barragem do rio.

A Comissão das Comunidades Européias ofereceu-se para mediar o conflito e, numa reunião das partes e da Comissão, em Londres, em 28.10.1992, as partes assumiram compromissos transitórios, incluindo que sua divergência seria submetida à CIJ, que uma missão tripartite analisaria a variante $C$ até 31.10 .1992 e que um groupo tripartite de expertos independentes proporia medidas de urgência a serem tomadas.

Em 01.01.1993, a Eslováquia tornou-se um Estado independente. Em 07.04.1993, ela e a Hungria firmaram o compromisso para submeter à CIJ o diferendo relativo ao projeto Gabcíkovo-Nagymaros. Pelo compromisso, as partes acordaram, enquanto tardasse a decisão definitiva da Corte, aplicar um regime temporário de gestão das águas do rio, regime cuja colocação em prática foi problemática. A barragem de Cunovo rapidamente levou a uma significativa redução da vazão e do nível no leito original após a barragem, bem como nos "braços" secundários do rio. Em 26.08.1993, os Estados acordaram na criação de um grupo tripartite (um experto nomeado por cada um, mais três nomeados pela Comissão das Comunidades Européias) para estudar os efeitos dessa redução e as medidas corretivas já tomadas, bem como para formular medidas apropriadas.

Em 01.12.1993, os expertos nomeados pela Comissão recomendaram a adoção de diversas medidas para remediar temporariamente a situação, mas não houve acordo entre as partes sobre essas recomendações.. Depois de longas negociações, concluíram, em 19.04.1995, um acordo sobre medidas técnicas temporárias e as vazões do Danúbio e de seu "braço" Moson, acordo que teria fim quatorze dias após o pronunciamento definitivo da Corte.

Eis o caso. A primeira questão submetida pelas partes à Corte era sobre o direito da Hungria de suspender e, depois, abandonar o projeto.

O cerne da razão de decidir da $\mathrm{CIJ}$ parece ter sido por ela resumido no ponto 39 do acórdão, em que ela registrou que as partes não contestavam que tanto o tratado de 1977 quanto o acordo de assistência mútua de 1977 e o protocolo de 1989 tinham sido validamente concluídos e estavam em pleno vigor durante o desenrolar de todos aqueles fatos que opuseram os dois Estados. A Corte acrescentou que as partes não contestavam que esses instrumentos, por mais flexíveis que fossem, não admitiam a possibilidade de os signatários suspenderem ou abandonarem unilateralmente os trabalhos ali previstos, muito menos executá-los conforme a um calendário que não tinha sido acertado de comum acordo entre as partes. 
O argumento principal da Hungria era um "estado de necessidade ecológica", do qual a Corte foi inteiramente esclarecida, tanto que o descreveu com detalhe (ponto 40 do acórdão), inclusive com menção aos estudos científicos juntados ao processo, comprovando o "estado de necessidade ecológica". Basicamente, a Hungria alegava que o regime previsto de utilização da barragem de Gabcíkovo para geração de eletricidade provocaria constantes mudanças na vazão e nos níveis do rio Danúbio e de seus "braços", ameaçando as espécies aquáticas. Essas variações também punham em risco, somadas a fatores como erosão e possível eutrofização decorrentes do mesmo regime, a qualidade das águas e a alimentação dos reservatórios subterrâneos, pois o Danúbio deixaria de funcionar como seu alimentador para ser seu dreno.

Quanto a Nagymaros, a barragem tornaria a água lodosa, comprometendo sua qualidade e o abastecimento baseado na captação nas margens. A operação da central hidrelétrica, também em "regime de ponta", ameaçaria, como em Gabcíkovo, as espécies aquáticas, por engendrar variações diárias significativas nos níveis da água. Ainda, haveria erosão do leito após a barragem, ao longo da ilha fluvial de Szentendre, fazendo baixar o nível das águas nesse trecho e diminuindo a produtividade dos poços de captação nas margens, com prejuízo para o abastecimento de Budapest.

A Hungria ainda argumentou que a Tchecoslováquia teria violado o tratado de 1977, especialmente as obrigações dos arts. 15 e 19, de zelat pela proteção da qualidade das águas e da natureza, ao insistir na continuação do projeto, sobretudo em Nagymaros, sem atentar para os perigos ecológicos que se evidenciavam. Os estudos sobre o potencial impacto ambiental do projeto incumbiam à Tchecoslováquia, mas a Hungria anotou que eles não foram conduzidos de maneira adequada. Finalmente, a Hungria observou que esse fator não estava sendo aventado para justificar seu abandono do projeto (pela quebra prévia do tratado pela outra parte), mas como mais um determinante do estado de necessidade ecológica.

Por sua vez, a Eslováquia, contrariamente à Hungria, afirmou a necessidade de se apreciar a suspensão e o abandono da execução de uma obrigação convencional dentro da moldura do direito dos tratados, mesmo porque a Convenção de Viena de 1969 só compilava o direito internacional costumeiro já existente. Ademais, após sua entrada em vigor, a Hungria ratificou sua participação no projeto pelo protocolo de 1989, que fazia parte de uma teia de tratados interligados, inclusive o tratado de 1977.

Sobre o estado de necessidade, a Eslováquia negou que pudesse ser um motivo para a suspensão de uma obrigação convencional, acrescentando que a "necessidade ecológica" ou o "risco ecológico", no âmbito da responsabilidade de Estados, não funcionariam como excludente da ilicitude de um ato. De qualquer forma, a Hungria teria exagerado na previsão de impactos negativos para o ambiente (por exemplo, a situação de operação do sistema descrita pela Hungria só ocorreria em casos excepcionais), além de que, ainda que se verificassem, poderiam ser remediados em grande extensão. 
A Eslováquia negou, ainda, que tivesse descumprido as obrigações de proteção da natureza e da qualidade das águas dos artigos 19 e 15, respectivamente, do tratado de 1977, salientando que a avaliação dos possíveis efeitos não lhe incumbiam exclusivamente, senão às duas partes, conforme o território em que se dariam as obras. Finalmente, sublinhou que a Hungria procedeu unilateralmente ao suspender e ao abandonar os trabalhos sem antes recorrer aos mecanismos de solução de controvérsias previstos no artigo 27 do tratado de 1977.

Seguindo seu entendimento anterior nessa matéria, a Corte confirmou que várias das disposições da Convenção de Viena sobre direito dos tratados de 1969 só codificavam o direito costumeiro já existente, como as relativas à extinção e à suspensão (art. 60 e 62). E não havia dúvidas de que, de qualquer forma, a Convenção se aplicava ao protocolo de 06.02.1989 entre as partes, pois aí já estava em vigor. De qualquer forma, a Hungria consideraria o Tratado de 1977 válido e em vigor, tanto que, em maio de 1992, comunicou sua terminação.

A Corte distinguiu os campos de aplicação do direito dos tratados e da responsabilidade de Estados, dizendo que o primeiro (codificado na Convenção de Viena de 1969) trata apenas das possibilidades lícitas de terminação dos tratados, as ilícitas entrando na questão da responsabilidade. Para a Corte, era fato que, apesar dos argumentos da Hungria, o efeito prático de seu ato foi tornar impossível a realização do projeto como inicialmente previsto, e que era expressamente qualificado de "único e indivisível". Assim, caso se verificasse o alegado estado de necessidade, ele só liberaria a Hungria da responsabilidade por descumprimento ilícito do tratado, mas não teria o condão de simplesmente desvinculá-la das obrigações decorrentes do tratado, nem significaria, por si só, que ela tenha agido conforme a essas obrigações, e tampouco a isentaria de reparar eventuais prejuízos à Tchecoslováquia.

Então, a Corte passou a apreciar a existência ou não de um estado de necessidade à luz do artigo $33^{3}$ do projeto da Comissão de Direito Internacional sobre responsabilidade internacional de Estados, que as partes elegeram como critério.

3 "Artigo 33. Estado de necessidade

1. O estado de necessidade não pode ser invocado por um Estado como uma causa de exclusão da lícitude de um fato desse Estado não conforme a uma de suas obrigações internacionais, a menos que:

a) esse fato tenha constituído o único meio de resguardar um interesse essencial do dito Estado contra um perigo grave e iminente; e que

b) esse fato não tenha ameaçado gravemente um interesse essencial do Estado a respeito do qual a obrigação existia.

2. Em qualquer caso, o estado de necessidade não pode ser invocado por um Estado como causa de exclusão de ilicitude

a) se a obrigação internacional à qual o fato do Estado não é conforme decorre de uma norma imperativa do direito internacional geral; ou

b) se a obrigação intemacional à qual o fato do Estado não é conforme é prevista por um tratado que, explícita ou implicitamente, exclui a possibilidade de invocar o estado de necessidade no que respeita a essa obrigação; ou

c) se o Estado em questão contribuiu à superveniência do estado de necessidade." (Anuário da Comissão do Direito Internacional, 1980, vol. II, segunda parte, p. 33, em tradução livre) 
Quanto à existência de um interesse essencial, a Corte referiu a opinião da própria Comissão do Direito Internacional, no sentido de que essa noção não deveria ser reduzida apenas à "existência", devendo-se admitir que se refira também a um perigo grave à conservação do ambiente no território de um Estado. A Comissão também tinha anotado que só recentemente, nas últimas décadas (antes de 1980), o equilíbrio ecológico veio a ser considerado como um "interesse essencial" de todos os Estados. Sobre o tema, a Corte lembrou seu próprio entendimento, numa opinião consultativa de 1996 ("Licitude da ameaça ou do emprego de armas nucleares"), de que existe uma obrigação geral dos Estados de garantir que as atividades exercidas no território sob sua jurisdição respeitem o ambiente nos outros Estados ou nas zonas ern que nenhum Estado tem jurisdição, e que essa obrigação geral faz parte do direito internacional ambiental.

Todavia, quanto às dúvidas da Hungria sobre os riscos representados pelo projeto, que a levaram a suspender e, depois, a abandonar a sua execução, a Corte anotou que, por mais sérias que fossem, não eram capazes de estabelecer, por si só, a existência objetiva de um perigo como elemento constitutivo do estado de necessidade. A Corte reconheceu que "perigo" envolve a noção de "risco", aí diferindo do prejuízo materializado; mas a mera apreensão a respeito de um perigo, sem a verificação da real existência desse perigo, não era suficiente para caracterizar o estado de necessidade. A esse entendimento contribuiria o requisito de que o perigo seja grave e iminente, o que é bem diferente de "eventualidade" (não excluída a possibilidade de enquadrar como iminente um perigo remoto no futuro, desde que certo e inevitável).

No entendimento da Corte, a Hungria não teria provado que o perigo alegado era real, grave e iminente, e que apenas as medidas que tomou eram capazes de evitá-lo. Referindose aos perigos descritos pela Hungria quanto ao setor de Nagymaros, a Corte afirmou que, embora eles pudessem vir a materializar-se, não eram iminentes no momento em que a Hungria decidiu suspender as obras, pois dependeriam da forma de exploração da hidrelétrica e das eclusas, o que ainda estava por ser definido no futuro.

Quanto ao aprofundamento do leito do rio depois de Nagymaros, a Corte observou que o alegado perigo para a alimentação de água de Budapest já se materializara antes de 1980, visto que a Hungria já tinha aprofundado o leito na região da ilha de Szentendre para retirar material de construção; então o perigo não decorria apenas do tratado de 1977. Ademais, a Hungria tinha à disposição outros meios de contornar esses problemas que não pelo abandono do tratado, como, por exemplo, depositar cascalho regularmente no leito do rio; quanto ao abastecimento de água, bastava tratá-la adequadamente, ainda que essa fosse uma alternativa mais dispendiosa.

Também as preocupações da Hungria com relação ao setor de Gabcíkovo a Corte afirmou referirem-se ao longo prazo e, mais importante, serem incertas. A Corte transcreveu trechos do relatório do comitê da Academia das Ciências da Hungria (23.06.1989), que afirmou expressamente não haver certeza sobre os efeitos ambientais do projeto, devendose proceder a estudos que levariam bastante tempo. Alêm disso, a própria Hungria se 
comprometera, no início de junho de 1989, a continuar os trabalhos em Gabcíkovo, tudo isso denotando que não se esperavam efeitos graves para o ambiente, muito menos iminentes. Outrossim, também ali a Corte considerava a Hungria em condições de adotar outras medidas para prevenir efeitos negativos, ao invés de simplesmente abandonar o projeto, pois ela poderia controlar o fluxo das águas na parte das obras que ficariam em território húngaro.

A Corte anotou que, embora os objetivos principais do tratado de 1977 fossem a produção de eletricidade, o melhormamento da navegação no Danúbio e a proteção contra $s$ inundações, a necessidade de proteger o ambiente não escapara às partes, como demonstravam os art. 15, 19 e 20.

O estado de necessidade não poderia ser invocado pela Hungria para liberar-se de suas obrigações também pelo fato de ela mesma ter contribuido para sua ocorrência, ao propor a aceleração dos trabalhos em 1989, quando os conhecimentos científicos já estavam mais evoluídos que em 1983, quando solicitara o retardamento do projeto (por razões econômicas mas, subsidiariamente, ecológicas).

Em conseqüência, afirmou a Corte, não havia necessidade de observar se a atitude da Hungria violara um interesse essencial da Tchecoslováquia, nem se a Tchecoslováqui descumprira suas obrigações de proteger a natureza inscritas no tratado de 1977 (art. 15 e 19) contribuindo para o alegado estado de necessidade, nem se a Hungria violara o art. 27 do tratado, sobre a necessidade de procurar os meios ali indicados para a solução de conflitos ao invés de proceder à adoção unilateral de medidas. Ou seja, todos esses argumentos foram sumariamente deixados à margem do julgamento, prejudicados em função do posicionamento adotado pela Corte nas outras questões.

A segunda questão submetida à Corte era se a Tchecoslováquia tinha o direito de colocar em prática a "variante C".

Pela "variante C", a construção da barragem propriamente dita começou em 23.10.1992 e continuou entre 24 e 27.10.1992. Entre outras obras, de $80 \%$ a $90 \%$ das águas do Danúbio foram dirigidas para o canal de alimentação da central hidrelétrica de Gabcíkovo

A Corte reconheceu que a, se a 'Tchecoslováquia considerava a atitude da Hungria como ilícita, poderia tê-la invocado para pôr fim ao tratado, mas isso não a conduziria a seu objetivo, que era a exploração do complexo Gabcíkovo-Nagymaros conforme previsto naquele tratado. A Eslováquia ainda justificou a variante $\mathrm{C}$ com o "princípio de aplicação por aproximação". No entanto, a Corte, observando que, pelo tratado de 1977, o sistema era uno e indivisível e destinava-se ao aproveitamento conjunto dos recursos, a variante $\mathrm{C}$, apesar da semelhança exterior com o projeto inicial, era juridicamente contrária a ele, porque unilateral. Além disso, a concordância da Hungira, dentro do projeto, com o desvio do Danúbio, só era válida para a sua execução de comum acordo entre as partes, mas não para um desvio (de $80 \%$ a 90\%) no âmbito de um projeto unilateral, considerando tratar-se de um rio internacional e, mais que isso, de fronteira entre os dois países. 
Quanto à necessidade, pelo direito internacional, de o Estado lesado procurar atenuar seus prejuízos, levantada pela Eslováquia sob a justificativa de que, nada tendo feito nesse sentido, não poderia, depois, reclamar indenização, a Corte contrapôs o fato de que essa situação não justifica a prática de um ato ilícito (como a variante C).

Já para admitir-se a solução da Tchecoslováquia como "contra-medida", assim liberando-a de ilicitude, ela deveria atender a determinados requisitos, e a Corte, aceitando o argumento da Hungria, considerou que ela não atendia, pelo menos, ao da proporcionalidade. Por isso, não havia sequer necessidade de avaliar outros requisitos, como o de que a "contramedida" tenha por fim incitar o Estado a cumprir suas obrigações, pois isso exigiria que a "contra-medida" fosse reversível, o que não era o caso.

Em conclusão, a Tchecoslováquia só estava autorizada a recorrer à variante $\mathrm{C}$ enquanto ela importava apenas obras que não dependiam da anuência da Hungria; porém, já não tinha o direito de colocá-la em operação a partir de outubro de 1992, passando por cima de interesses e dos direitos da Hungria sobre o Danúbio. Vale dizer, foi só ao desviar de fato as águas do Danúbio para o canal de derivação, em outubro de 1992, que ela violou o tratado de 1977.

A terceira questão submetida à Corte era sobre os efeitos da comunicação, pela Hungria, da terminação do tratado.

Foram mencionados, no acórdão, todos os argumentos da Hungria para justificar. a decisão de denunciar o tratado de 1977 , inclusive o aparecimento de novas normas de direito internacional ambiental, aí compreendida a necessidade de proteção da biodiversidade (decorrente da Declaração do Rio de 1992) e o princípio da precaução; a Hungria relevara também a transformação de um tratado em princípio atento à proteção ambiental (art. 15, 19 e 20) em "portador de catástrofes ecológicas". A Corte tampouco ignorava as recentes recomendações do desenvolvimento sustentável. Não obstante, pautou sua decisão tãosomente pelo direito dos tratados, conforme a Convenção de Viena de 1969, e observou também que os desenvolvimentos do direito ambiental não teriam inserido normas $j u s$ cogens no âmbito internacional, que pudessem prevalecer sobre o tratado preexistente.

Não havendo no Tratado de 1977 a previsão de hipóteses de sua finalização, a Corte entendeu que só de comum acordo poderiam as partes dar fim ao tratado (ainda que houvesse motivos para justificar a suspensão temporária, enquanto perdurasse o estado de necessidade, por exemplo), pois o projeto inicial era de um sistema único e de gestão conjunta. De qualquer forma, para a terminação do tratado, não era relevante a alteração das condições políticas, porque não constituíam o objeto do tratado inicial. Quanto à redução da rentabilidade esperada do investimento, em extensão cada vez maior, não ser tão grande, na opinião da Corte, a ponto de justificar o abandono do tratado. Quanto aos "novos desenvolvimentos da ciência no campo da proteção ambiental", os art. 15, 19 e 20 do tratado de 1977, concebidos numa perspectiva de evolução, permitia às partes atender a essas novas exigências de ordem ambiental, conciliando-as com os interesses econômicos, sem alterar profundamente o acordo. 
A propósito, a Corte recapitulou sua própria posição, manifestada na opinião consultativa sobre a "Licitude da ameaça ou do emprego de armas nucleares", de 1996, no sentido de que "o ambiente não é uma abstração, mas o próprio espaço onde vivem os seres humanos e de que depende a qualidade de suas vida e saúde, inclusive para as gerações futuras" (ponto 112 do acórdão). Nessa mesma linha, a Corte expressou sua convicção na necessidade de avaliarem-se continuamente os riscos ecológicos, até porque cada vez mais reiterada no âmbito internacional desde a conclusão do tratado de 1977 entre Hungria e Tchecoslováquia, tornando seus art. 15, 19 e 20, por isso, ainda mais pertinentes.

Em que pese a todas essas manifestações de ciência das recentes, mas importantes e cada vez mais fortes exigências de ordem ambiental, a Corte achou por bem não criar um precedente de exceçãoà regra pacta sunt servanda para admitir a terminação unilateral de um tratado com base apenas em violações recíprocas.

Considerando isso tudo, bem como a obrigação dos Estados, inscrita no direito dos tratados, de dar execução aos tratados de boa fé, a comunicação, pela Hungria, em 19.05.1992, da terminação do tratado, a contar de 25.05.1992 (portanto apenas seis dias depois), não podia ter o condão de colocar-lhe fim verdadeiramente, até porque em nenhuma dessas datas a Tchecoslováquia teria violado o tratado (como visto, a Corte entendeu que a violação pela Tchecoslováquia só ocorreu no momento em que desviou as águas do Danúbio, em outubro daquele ano), ou seja, não havia possível prejuízo para a Hungria. Mas a Corte fez questão de observar que, por seu comportamento até então, a Hungria perdera o direito de pôr fim ao tratado, ainda que a Tchecoslováquia tivesse já violado uma disposição essencial para a realização do objetivo do tratado.

Quanto às indenizações a que fariam jus as partes, a Corte observou que, tendo ambas agido com violação do direiro internacional, causando-se prejuízos mutuamente, ambas mereciam indenização pelos respectivos danos. Não fora pedido à Corte que determinasse os montantes, senão apenas que estabelecesse o que deveria ser considerado para a liquidação num momento posterior ao acórdão. Assim, a Corte referiu particularmente os prejuízos da Hungria na exploração dos recursos hídricos, por ter a Tchecoslováquia desviado quase todo o fluxo original para o canal de derivação conducente à hidrelétrica; referiu também os prejuízos da Tchecoslováquia com o abandono, pela Hungria, dos trabalhos em Nagymaros e Dunakiliti, já que isso causou atraso na conclusão da central de Gabcíkovo e mudanças no seu funcionamento. Porém, embora merecendo ambas as partes indenização, a Corte sugeriu o concerto entre elas para o aproveitamento conjunto do complexo que foi, afinal, construído, e a renúncia às respectivas reparações, ressalvado a acerto de contas das obras levadas a cabo.

É importante anotar que a Hungria, por sua parte, tinha relevado prejuízos de suma importância do ponto de vista ecológico: à fauna, à flora, aos solos, ao subsolo, ao lençol freático e ao aquífero, entre outros (ponto 127). Já a Eslováquia demandava reparação, entre outros, dos custos com que arcou sozinha no setor de Gabcíkovo, na manutenção da navegabilidade do Danúbio até que estivesse funcionando um novo canal e na execução da 
variante $\mathrm{C}$; das perdas no setor de Nagymaros com relação à navegação e à proteção contra inundações; e da perda de produção de energia (ponto 129).

Mas a Corte observou que a varainte $C$ já estava operacional havia quase cinco anos, não havendo motivo para demolir o complexo; por outro lado, o setor de Nagymaros não avançara, e nada recomendava mudança ali, em vista da falta de acordo entre as partes. $\mathrm{Ou}$ seja, quanto a Gabcíkovo, a Corte preferiu dar guarida ao fato consumado, o que é perigoso como precedente (apesar de não ser o primeiro exemplo), porque pode estimular atos extremamente temerários tanto com relação ao ambiente como em outros campos. Por outro lado, a Corte foi ponderada ao notar que a manutenção daquela situação, com um futuro acordo sobre a gestão do sistema e do aproveitamento dos recursos, bem como a devida repartição dos custos, poderia levar à consecução dos objetivos do tratado de 1977, inclusive a proteção do ambiente e da qualidade das águas (pontos 133 a 137).

Sobre o futuro do projeto, a Corte apenas disse incumbir às partes entrarem em aćordo com relação a sua continuidade ou não e, em caso afirmativo, à gestão dos recursos. No que tange à necessidade de proteção da natureza e da qualidade das águas, a Corte limitou-se a observar que seria bom levar em conta as implicações do projeto sobre o ambiente, até em função da obrigação inscrita no próprio tratado, em seus art. 15 e 19. Ficou registrada a ciência quanto ao caráter freqüentemente irreversível dos danos ambientais e quanto aos limites dos mecanismos de reparação. A Corte não deixou de anotar também que várias exigências ambientais tinham sido enunciados em diversos instrumentos internacionais ao longo das últimas décadas, e que o conceito de desenvolvimento "durável" (sustentável) resumia a necessidade de conciliar desenvolvimento econômico com a proteção da natureza.

A contribuição básica da Corte é a recomendação de retorno ao regime inicialmente previsto no tratado de 1977 e protocolos (visto que concluía que ele permanecia em vigor), com as devidas adaptações à situação atual, considerando o que fora realmente executado. Porém em conclusão, a Corte devolveu às partes o problema que elas the haviam proposto; as partes é que deveriam encontrat uma solução para o futuro do projeto, à luz da necessidade de proteger o ambiente, a qualidade das águas etc. Quanto à Corte, ela só levou em consideração o direito dos tratados, reduzindo seu trabalho a uma simples subsunção, sem nada avançar sobre a precaução ou outras questões de proteção ambiental.

Em princípio, seria até desejável deixar que as partes decidissem de comum acordo sobre a posição a adotat com relação àquele empreendirnento, pois eram seus interesses que estavam em jogo, num dissídio fruto de um tratado concluído apenas entre elas. No entanto, verificado que as partes já haviam chegado a um impasse que praticamente impossibilitava qualquer avanço nas negociações diplomáticas, a Corte perdeu deliberadamente a oportunidade de desenvolver as normas de direito internacional ambiental, em particular a precaução.

Ao desautorizar a Hungria a invocar o estado de necessidade (ecológica) por ter ela mesma contribuido à sua superveniência, a Corte não deu importância a que o fato de ter agido errado no passado não deve condenar um Estado a continuar prejudicando o ambiente, 
ainda mais quando esse Estado já percebeu o perigo dessa conduta. Em várias passagens, Corte recomendou, direta ou indiretamente, a conclusão das obras, apesar dos riscos alegados pela Hungria. A proposta seria justificada pela possibilidade de se dar às instalações um uso que atendesse às necessidades de otdem ambiental. Entretanto, se a Corte mesma propugna que se evite o desperdício do investimento já realizado (com as obras iniciadas), não é razoável esperar que os interessados realizem dispêndios ainda maiores para concluir o projeto e, ao final, não lhe dêem a destinação inicialmente prevista, pois, nesse caso, todo o investimento teria sido inútil.

Outra sugestão da Corte era a adoção de medidas posteriores para contornar o impacto já causado, como o indefinidamente repetido depósito de cascalho no fundo do rio para minimizar a erosão e o tratamento "adequado" da água depois de comprometida sua qualidade, ainda que essas medidas fossem mais dispendiosas que a prevenção. Esse posicionamento é totalmente contrário ao princípio amplamente aceito em direito internacional ambiental de que é mais barato prevenir que reparar o dano ecológico.

Essas propostas da Corte decorrem certamente da sua insistência em aplicar apenas o direito dos tratados, posição que ela não esconde em nenhum momento. $O$ fundamento para preterir as normas de direito internacional ambiental é que elas ainda não constituiriam jus cogens. Ora, normas assim só podem cristalizar-se como costumeiras se lhes for dado trânsito; senão, continuarão sem força imperativa, pois não é só o tempo de existência de uma norma que the confere essa força.

\subsection{Organização Mundial do Comércio}

Dois casos de reclamações apreciadas no âmbito da Organização Mundial do Comércio merecem referência para os fins deste trabalho: o dos padrões dos Estados Unidos para gasolina reformulada e convencional e o das restrições das Comunidades Européias à importação de carne produzida com hormônios de crescimento. As reclamações voltam-se contra medidas destinadas à proteção da saúde e do ambiente, reputadas como barreiras ao comércio mundial.

\section{O caso dos padrões para gasolina reformulada e convencional}

No relatório WT/DS2/AB/R (29.04.1996), o Órgão de Apelação da OMC apreciou a apelo dos Estados Unidos contra as conclusões (29.01.1996) do Painel estabelecido para solucionar litígio em torno da regulamentação da gasolina adotada por aquele país. A disputa começou por iniciativa da Venezuela, em 23.01.1995, posteriormente acompanhada pelo Brasil. Também figuraram como terceiros interessados as Comunidades Européias e a Noruega.

O Clean Air Act (CAA) dos Estados Unidos data de 1963, mas foi em 1990 que o Congresso determinou que a agência americana de proteção ambiental, a EPA(Environmental Protection Agency), adotasse regulamentos para melhorar a qualidade do ar nas áreas mais poluídas, por meio da redução da emissão de poluentes por veículos. Assim, a EPA instituiu 
as Regras para Combustíveis e Aditivos - Padrões para Gasolina Reformulada e Convencional, que constituem a Parte 80 do Título 40 do Código de Regulamentações Federais (Code of Federal Regulations).

Previu-se que só gasolina reformulada puderia ser consumida nas áreas que enfrentaram os níveis mais críticos de poluição no período 1987-1989; no restante do país, poderia ser comercializada a gasolina comum. A gasolina reformulada deveria atender a padrões rígidos, enunciados no CAA, a fim de garantir sua limpeza. Simultaneamente, a gasolina convencional deveria permanecer no mesmo nível de limpeza de 1990, impedindo que produtores, refinarias e importadores colocassem na gasolina convencional os elementos proibidos para a reformulada.

Para a gasolina convencional, permitiram-se padrões individuais, conforme os dados da gasolina refinada, misturada ou importada em 1990. Já para as empresas que tivessem operado por menos de seis meses em 1990 ou que começassem a operar ainda depois, bem como para os importadores que também eram refinarias no estrangeiro e que, até aquele ano, importavam de sua refineria menos de $75 \%$ da gasolina que comercializavam nos Estados Unidos, estabelecia-se um padrão geral mais restritivo.

Com relação à gasolina de nova fórmula, de 1995 até 1998, os padrões seriam estabelecidos a partir das bases individuais ("modelo simples"), mas os importadores ficariam sujeitos a um critério conforme aquele padrão geral mais restritivo. Em 1998, entraria em vigor o "modelo complexo", em que deixariam de valer os padrões individuais, devendo todas as empresas antender ao mesmo nível de exigências.

Em maio de 1994, a EPA propôs que se admitissem padrões individuais também para importadores a que, até então, não eram aplicáveis. Essa hipótese envolvia uma investigação prévia da procedência da gasolina, com critérios mais rigorosos que os exigidos na determinação dos padrões individuais das empresas que trabalhavam com gasolina nacional. Todavia, em setembro daquele ano, o Congresso negou fundos à EPA para implementar essa proposta. Continuaram em vigor, então, as determinações anteriotes.

O Painel referente às reclamações de Venezuela e Brasil contra a lei da gasolina americana concluiu, entre outros, que a gasolina importada e a nacional eram produtos similares, portanto não se justificando a imposição de regras menos favoráveis à importada, já que isso feria o art. III:4 do GATTT 1994 ("Acordo", "Acordo Geral"). Desse modo, embora reconhecendo que o "ar puro" é um recurso natural esgotável, conforme o art. XX, " $\mathrm{g}$ " do Acordo, esse dispositivo não justificava as medidas incompatíveis com o art. III:4.

A propósito, o art. XX, "g", do GATT 1994 autoriza medidas relativas à conservação dos recursos naturais não renováveis, se também são aplicadas restrições à produção ou ao consumo nacionais. Pelo caput desse artigo, o Acordo não deve impedir a adoção de tais medidas por um Estado-Parte, desde que elas não sejam aplicadas de maneira a consituir uma discriminação arbitrária ou injustificável entre países em que as mesmas condições estão presentes, nem uma restrição disfarçada ao comércio internacional. 
Na tentativa de reverter as conclusões do Painel, de maneira a enquadrar no art. XX, "g", o tratamento menos favorável conferido ao produto importado, os Estados Unidos repisaram a suposta dificuldade de se determinar a procedência da gasolina estrangeira e sua observância dos requisitos aplicados à gasolina americana.

No entanto, o Órgão de Apelação fez eco à constatação do Painel no sentido de que, embora pudesse ser realmente difícil constatar a origem e a qualidade da gasolina importada, não se justificava a restrição do uso, pelos produtores estrangeiros, dos mesmos critérios dos nacionais americanos para a determinação dos padrões individuais. Afinal, a determinação da origem e do preenchimento de determinadas condições é prática corrente com relação a outros produtos. É certo que a cooperação dos países exportadores interessados se faria necessária, mas os Estados Unidos não demonstraram que Venezuela ou Brasil houvessem negado sua colaboração.

Outra falha dos Estados Unidos consistiu em não avaliar os custos e dificuldades dos exportadores para adaptarem-se aos novos critérios, tendo em conta que um de seus argumentos para assegurar tratamento mais benéfico à gasolina americana eram justamente os custos que uma adequação imediata demandaria, sendo necessárias mudanças em quase todas as refinarias americanas.

A conclusão do Órgão de Apelação, enfim, foi no sentido de que, embora a regulamentação da gasolina instituída no âmbito do Clean Air Act pudesse ser considerada uma exceção prevista no art. XX, "g", do GATT 1994 (diferentemente da posição do Painel a esse respeito), ela não encontrava respaldo dentro do conjunto daquele artigo, pois constituía uma discriminação injustificável e uma restrição disfarçada ao comércio internacional, o que o caput do art. XX não permite. Ou seja, o efeito prático das constatações do Painel não foi alterado, qual seja, a recomendação de que o Órgão de Solução de Disputas determinasse aos Estados Unidos a adequação da sua lei da gasolina ao disposto no art. III:4 do GATT 1994 (mesmo tratamento para produtos similares nacionais e importados).

Mas o Órgão de Apelação fez questão de enunciar as implicações que essa decisão não tinha. Nesse sentido, afirmou que os Estados-Partes podetn, sim, tornar as medidas que julgarem necessárias para combater a poluição atmosférica e o ambiente em geral. Aliás, no preâmbulo do Tratado da OMC e na Decisão sobre o Comércio e o Meio Ambiente (adotada no Comitê de negociações comerciais em Marrakesh, em 14.04.1994), foi expressamente reconhecida a importância de coordenar as políticas comerciais e ambientais. A única limitação à autonomia dos Estados para estabelecer regras de proteção ambiental, inclusive sobre as relações entre ambiente e comércio, é a necessidade de respeitar as regras do GATT.

No caso "Padrões para gasolina reformulada e convencional", não há como saber se a verdadeira intenção dos Estados Unidos com os padrões mais exigentes para a gasolina estrangeira era beneficiar o produto nacional. O que foi constatado no âmbito da OMC é, simplesmente, que a regulamentação teve esse efeito na prática. 
Talvez se justificasse, pela ótica da precaução, o receio dos Estados Unidos quanto às dificuldades na determinação da qualidade da gasolina importada, que poderiam minar o projeto de despoluição do ar. Com efeito, não havendo como determinar com certeza a adequação de alguma gasolina aos padrões definidos para assegurar a melhoria da qualidade do ar, a precaução não impede (e, antes, recomenda) a adoção de medidas que impeçam um impacto negativo maior sobre o ambiente; no caso, a rejeição da gasolina de qualidade obscura. Porém, a OMC decidiu conforme os fins a que se destina, ou seja, o levantamento de toda atitude restritiva ao comércio internacional.

\section{O caso das restrições das Comunidades Européias à importação de carne produzida} com hormônios de crescimento

O caso "Hormônios" (WT/DS26/AB/Re WT/DS48/AB/R) consistiu na reclamação de Estados Unidos e Canadá, perante o Órgão de Solução de Disputas da OMC, contra a restrição das Comunidades Européias à colocação no mercado interno e à importação de carne e de produtos derivados de carne de terceiros países que empregassem determinados hormônios de crescimento. ${ }^{4}$ Para as Comunidades, seu posicionamento estaria respaldado pela Acordo sobre Medidas Sanitárias e Fitossanitárias (Sanitary and Phitossanitary Measures Agreement - SPS), considerando o caráter cancerígeno dos hormônios indicados nas suas Diretivas.

Figurando no tratado que estabeleceu a Organização Mundial do Comércio, o SPS Agreement, que entrou em vigor em 01.01.1995, faz parte, junto como outros acordos, da Acta Final da rodada Uruguai do GATT, concluída em 15.04.1994, em Marrakesh.

O painel sobre a reclamação dos Estados Unidos foi estabelecido pelo Órgão de Solução de Disputas em 20.05.1996; o painel sobre a reclamação do Canadá, em 16.10.1996. Os relatórios desses painéis circularam entre os membros da Organização em 18.08.1997. Entre 24.09.1997 e 20.10.1997, as Comunidades Européias, Estados Unidos, Canadá e terceiros países (Austrália, Nova Zelândia e Noruega) apresentaram recursos.

No âmbito do Órgão de Solução de Disputas, em suma, foram atendidas as pretensões de Estados Unidos e Canadá quase na íntegra, com o argumento de que o SPS Agreement só autorizava a adoção de medidas assim com base em evidência científica. Questionou-se justamente a suficiência das provas apresentadas pelas Comunidades Européias. No máximo, admitia-se que os dados apresentados permitiam concluir que hormônios de crescimento, genericamente falando, podem causar câncer, mas não que os exatos hormônios empregados por Estados Unidos e Canadá apresentavam a mesma característica, pois não teriam sido objeto de análise pelas Comunidades. Já os exportadores alegavam deterem estudos comprovando a não-periculosidade de seus hormônios (apesar das infrutíferas instâncias das Comunidades para que se lhes mostrassem esses estudos).

4 Diretivas do Conselho da então Comunidade Econômica Européia números 81/602/CEE (31.07.1981), 88/146/CEE (07.03.1988) e 88/299/CEE (17.05.1988), substituídas, em 1996, pela Direitva 96/22/EC da Comunidade Européia (29.04.1996). 
Perante o Órgão de Apelação, releva que as Comunidades requeriam a adequação da decisão com o princípio da precaução, insculpido no art. 5.7 do SPS Agreement, que autoriza a adoção de medidas sanitárias e fitossanitárias para proteção da saúde e da vida ainda na ausência de evidência científica, embora provisoriamente.

Em seu relatório (concluído em 05.01.1998 e circulado entre os membros da Organização em 16.01.1998), o Órgão de Apelação expressamente recusou-se a determinar a posição hierárquica do princípio da precaução. Observando que ainda muito se dișcute em torno de seu status, e reconhecendo que alguns sustentam a existência de um princípio de direito internacional ambiental costumeiro, afirmou que só dificilmente se poderia admitila como um princípio geral de direito internacional costumeiro. Considerou, assim, não dever manifestar-se sobre o status de um tal princípio (embora notando que se trata de uma questão importante), pois ele não poderia, por si só, exluir a aplicação dos princípios normais (de direito internacional costumeiro geral) na interpretação de tratados.

Vale frisar que o Órgão de Apelação da OMC admitiu também expressamente a importância de se determinar a posição do princípio da precaução no ranking das normas de direito internacional, e não deixou de registrar que o via inscrito no SPS Agreement, nomeadamente no sexto parágrafo do preâmbulo e nos artigos 3.3 e 5.7 .

O Acordo sobre Medidas Sanitárias e Fitossanitárias, em suma, garante aos signatários a adoção de medidas dessa ordem para a proteção da vida e da saúde humana, animal e vegetal, conforme o seu art. 2.1 (o art. 2 é intitulado "Direitos e Obrigações Básicos"), desde que não constituam medidas disfarçadas tendentes a restringir o comércio internacional (art. 2.3). Mas o art. 2.2 ainda impõe a limitação de que as medidas devem ser tomadas apenas na medida mínima necessátia para a proteção da saúde e da vida, e sempre com base em evidências científicas.

É muito restrita, portanto, a possibilidade de adoção de medidas assim. Mas o próprio art. 2.2 abre uma exceção para o art. 5.7, que autoriza a adoção de medidas mesmo sem evidência científica suficiente, porém apenas provisoriamente, e sempre com base na informação pertinente disponivel. O Estado que adotar medidas nessas circunstâncias deve providenciar na busca de mais informações e revisar suas medidas dentro de um período de tempo razoável.

Aí é que a precaução está mais patente, pois os demais dispositivos autorizando medidas sanitárias e fitossanitárias são bastante restritivos. Embora esteja presente a preocupação com a proteção da saúde e da vida, exige-se sempre uma justificativa científica, como o art. 3.3, ao autotizar que um Estado estabeleça padrões de segurança mais elevados que outros. Sobretudo, além de basearem-se em certeza científica, esses padrões devem estar em consonância com o objetivo principal de minimizar os impactos negativos no comércio (não no ambiente), conforme o art. 5.4. Ou seja, os membros não são obrigados a mudar os níveis de proteção que entendem adequados (sexto parágrafo do preâmbulo), desde que não representem entrave ao comércio internacional e decorram de evidências científicas. 
De fato, o acordo sobre medidas sanitárias e fitossanitárias desenvolve o art. XX do GATT, que já previa a possibilidade de os membros atuarem sobre o comércio a fim de proteger a saúde e a vida humana, animal e vegetal, desde que, assim agindo, não estabelecessem medidas protecionistas disfarçadas. Portanto, o SPS Agreement não tem como objetivo principal a proteção da saúde e da vida, senão apenas coibir a adoção de medidas protecionistas para os produtos e produtores nacionais sob a justificativa daquela proteção.

Por isso, previsivelmente, são bastante limitadas as situações em que o SPS Agreement autoriza a adoção de medidas sanitárias e fitossanitárias. Ainda assim, não se pode deixar de reconhecer que a recomendação de precaução está presente, sobretudo no art. 5.7, como o próprio Órgão de Apelação notou. O Órgão também admitiu o argumento das Comunidades Européias no sentido de que aquele dispositivo não exaure a relevância do princípio da precaução.

Então, ainda quando não fosse por um imperativo autônomo de direito internacional ambiental, o Órgão de Apelação da OMC poderia ter adotado uma atitude de precaução porque ela está, sim, prevista no próprio SPS Agreement, aliás como o Órgão de Apelação mesmo notou. A importância da questão ambiental tampouco lhe passou despercebida. Porém, como esperado, a decisão foi coerente com o objetivo principal do SPS Agreement e da OMC, que é, afinal, levantar os entraves ao comércio internacional.

A solução, portanto, foi similar àquela encontrada no caso dos padrões para gasolina reformulada e convencional. Todavia, ali, como visto, a tese dos Estados Unidos fundava-se apenas no GAT'T, que autoriza medidas de proteção à saúde e ao ambiente como exceção, e desde que não representem empecilhos ao comércio. Já aqui, embora as mesmas restrições se imponham para a adoção de medidas sanitárias e fitossanitárias, o art. 5.7 do SPS Agreement as flexibilizava, em nome da precaução, para admitir essas medidas mesmo na ausência de certeza científica sobre os impactos ambientais negativos que se quer evitar.

É claro que essa regra não serve para se deixar de observar as demais disposições do SPS Agreement ou do GATT, mas a solução do caso Hormônios perdeu de vista que as medidas de proteção ambiental, no âmbito dos acordos da OMC, sempre devem redundar em restrição ao comércio, exatamente para evitar os efeitos ambientalmente negativos que se atribui ao ptoduto em questão. A exceção contida no art. 5.7 do SPS Agreement não deveria poder ser excepcionada pela própria regra à qual esse artigo faz exceção.

\subsection{Tribunal Internacional para o Direito do Mar}

O Tribunal Internacional para o Direito do Mar (ITLOS - International Tribunal for the Law of the Sea) é um mecanismo de solução de controvérsias previs to no âmbito da Convenção das Nações Unidas sobre o Direito do Mar (UNCLOS - United Nations Convention on the Law of the Sea), de 10.12.1982 (aberta para adesões, em vigor desde 16.11.1994). No caso Bluefin Tuna, narrado a seguir, essa Corte deu um passo importante 
para o avanço da precaução, especialmente para a conservação e o aproveitamento de pescados, mas com reflexos também para o meio ambiente em geral.

Percebendo o decréscimo da população de determinada espécie de atum, Austrália, Nova Zelândia e Japão, que têm nesse pescado importante atividade econômica, resolveram repor os estoques naturais. Para tanto, instituíram entre si um sistema de quotas voluntárias de pesca a partir de 1985. No entanto, esse sistema verificou-se insuficiente, e os Estados adotaram uma convenção para a proteção desse atum (Convention for the Conservation of the Southern Bluefin Tuna, maio de 1993, entrando em vigor em 20.05.1994).

O atum da espécie Thunnus maccoyii (Southern Bluefin Tuna - SBT), foi historicamente alvo de uma atividade pesqueira (por métodos como linha comprida de pesca pontilhada de anzóis ou redes envolvendo cardumes inteiros, por exemplo) que levou a essa diminuição da biomassa. Além disso, o atum, cujo único local conhecido de reprodução é o Oceano Índico, ao sul de Java, na Indonésia, só se reproduz a partir de oito anos de idade, porém era pescado comercialmente já com dois ou três anos.

Assim, a convenção entre Austrália, Nova Zelândia e Japão constituiu um importante passo para o gerenciamento do atum, sobre o qual um dos maiores problemas era justamente a incerteza sobre a biomassa. Um dos aspectos mais significativos do tratado foi o estabelecimento de uma Comissão (Commission for the Conservation of the Southern Bluefin Tuna - CCSBT), auxiliada por um Comitê Científico consultativo. No seio da Comissão, as partes, com votos de peso igual, estabeleciam a quantidade total de pesca permitida (Total Allowable Catch - TAC) e a quantidade anual de cada Estado (alocação nacional), entre outras medidas.

Tanto a utilização ótima atual (no presente) do atum quanto sua conservação são objetivos da Convenção entre os três Estados. Contudo, visto que as decisões no âmbito da Comissão devem ser adotadas por unanimidade, com o Japão enfatizando a exploração e Austrália e Nova Zelândia, a conservação do atum, surgitam divergências sobse a quantidade total permitida (TAC) e a alocação nacional.

Num primeiro momento, as partes haviam concordado com o empreendimento de um esforço para, até 2020, repor os estoques aos níveis de 1980, para tanto comprometendo-se, entre outros, a restringir as quotas de pesca desde 1989, evitar a pesca de indivíduos muito jovens ou nas zonas de reprodução, desenvolver técnicas para reduzir a captura não intencional de albatroz, desenvolver programas de monitoramento e coleta de dados, bem como intensificar a pesquisa sobre o atum. Apesar disso, divergências sobre se o estoque estava ou não sendo reposto impediu um acordo sobre o quantidade total para 1998, pois Austrália e Nova Zelândia opunham-se ao desejo do Japão de aumentá-la.

Mantida a quantidade total permitida, o Japão decidiu empreender unilateralmente um programa de pesca experimental (Experimental Fishing Program - EFP), com a justificativa de tentar resolver a incerteza sobre a avaliação qque se tinha do estoque do atum, mas esse programa exigia pesca adicional, além da quota nacional. Conquanto favoráveis, em 
princípio, a estudos desse tipo, Austrália e Nova Zelândia não concordaram com a implementação do projeto japonês nesses termos, fora da moldura estabelecida no âmbito da Comissão e com aumento, na prática, da quota nacional daquele país.

Sem possibilidade de uma solução negociada entre as partes, e sem acordo entre as partes sobre o mecanismo de resolução de conflitos ao qual submeter a questão, Austrália e Nova Zelândia decidiram levá-la a arbitragem. Isso é autorizado no anexo VII da Convenção das Naçōes Unidas sobre o Direito do Mar (UNCLOS) para esse caso de falta de concordância quanto ao procedimento de solução de conflitos dentro da moldura do art. 287 UNCLOS (por vezes referida como "arbitragem compulsória") ${ }^{5}$. Pendendo, porém, a constituição do tribunal arbitral, o art. 290(5) UNCLOS autoriza a solicitação de medidas provisionais ao Tribunal Internacional para o Direito do Mar (ITLOS).

Assim, Austrália e Nova Zelândia protocolaram, em 30.07.1999, um requerimento de medidas provisionais contra o Japão. Alegando que o programa de pesca experimental redundava numa violação dos obrigações de conservar o atum, oferecendo um risco de dano irreversível à biomassa da espécie, requereram, entre outros, a imediata cessação desse programa e o desconto da quantidade assim pescada até então da alocação anual nacional japonesa. Também foi pedido que o Tribunal ordenasse às partes agir em consonância com o princípio da precaução até a decisão final na disputa, abstendo-se de qualquer ato tendente a agravar a situação e dificultar a resolução.

O Japão respondeu, em 09.08.1999, questionando a competência do Tribunal, asseverando que, em todo caso, não poderia outorgar medidas provisionais. Mas actescentou que seu programa não representava risco de dano irreparável para a população do atum e que a situação não era de urgência, até porque Austrália e Nova Zelândia poderiam ser futuramente compensadas, se assim decidisse o órgão de arbitragem, com a redução da quota nacional do Japão pela quantidade pescada no progtama experimental. E requereu medidas provisionais por seu turno (para o caso de o Tribunal julgar-se competente), para que aqueles dois países retomassem as negociações para alcançar-se consenso sobre a quantidade total de pesca permitida (TAC) e sobre a continuação do programa experimental de forma conjunta.

Em 27.08.1999, considerando-se competente, nos termos da Convenção das Nações Unidas sobre o Direito do Mar (UNCLOS), na parte relativa à solução de conflitos, o Tribunal baixou uma ordem com medidas provisionais para enquanto não se estabelecesse o órgão arbitral, incluindo: que as partes, salvo acordo em sentido diverso, retomassem as últimas quotas de pesca estabelecidas, e que, na fixação das quotas para 1999 e 2000, fosse contada a quantidade capturada no programa de pesca experimental; que, sem unanimidade entre elas, as partes não desenvolvessem programas experimentais envolvendo a pesca de mais atum,

5 Cfe. SCHIFFMAN, Howard S. The Southern Bluefin Tuna Case: ITLOS hears its first fishery dispute. In: Journal of International Wildlife Law and Policy, 1999, 2(3), disponível em www.jiwlp.com, p. 6, nota de rodapé $n^{\circ} 55$. 
a não ser que as quantidades assim pescadas contassem para a alocação nacional anual; que as partes retomassem negociações para o gerenciamento do atum e empreendessem esforços para sua conservação e exploração ótima.

Foi a segunda disputa a passar pelo Tribunal Internacional para o Direito do Mar (ITLOS), mas a primeira a envolver uma questão de pesca $\mathrm{e}$ a permitir-lhe determinar medidas provisionais.

A decisão da Austrália e da Nova Zelândia de requisitar medidas provisionais ao Tribunal Internacional para o Direito do Mar enquanto não se instalasse a arbitragem de sua disputa com o Japão foi uma demonstração de confiança nesse órgão, ${ }^{6}$ o que só faz aumentar a importância de seu papel no desenvolvimento do direito internacional. Essa importância evidencia-se especialmente quando se recorda que, pelo menos no que respeita a suas decisões provisionais, suas determinações têm força vinculante, como se conclui do art. 290(6) UNCLOS, que determina que as partes devem adequar-se ("shall comply") às medidas provisionais prescritas pelo ITLOS (o modal "shall" é forte, antes impondo uma obrigação firme que fazendo uma recomendação, caso de "should"). ${ }^{8}$

No caso Bluefin Tuna, as medidas provisionais adotadas pelo ITLOS indicam uma recomendação de mudança de atitude frente aos imperativos de ordem ambiental, especialmente nas questões sobre que ainda não há certeza científica quanto aos impactos ecológicos. $\mathrm{O}$ concernimento do Tribunal com a questão ambiental ficou claro na declaração do juiz Laing, segundo o qual o Tribunal adotava uma "aproximação precautiva" ("precautionary approach"), assim evitando falar em "princípio da precaução" e enfrentar a discussão sobre se um tal princípio já era reconhecido no direito costumeiro, ao mesmo tempo em que colocava a decisão do Tribunal a salvo, pelo menos, da crítica de pouca flexibilidade. ${ }^{9}$

De toda sorte, ficou clara a recomendação do Tribunal aos Estados no sentido de procurar sempre agir na base do consenso e evitar medidas unilaterais, sobretudo quando a precaução se recomenda.

\subsection{Mercosul}

No âmbito do Mercosul, os tribunais ad hoc para solução de conflitos depararamse, até o moment, com dois casos que poderiam suscitar implicações ambientais: o caso dos pneumáticos remoldados provenientes do Uruguai e o dos produtos fitossanitários provenientes da Argentina.

\footnotetext{
${ }^{6}$ Cfe. SCHIFFMAN, op, cit., p. 15.

${ }^{7}$ Art. 290(6) UNCLOS: "The parties to the dispute shall comply with the provisional measures prescribed under this article".

${ }^{8}$ Cfe. SCHIFFMAN, op. cit., p. 10.

${ }^{9} \mathrm{Cfe}$. SCHIFFMAN, op. cit., p. 11.
} 


\section{Laudo Arbitral - Proibição de importação de pneumáticos remoldados procedentes do Uruguai (09.01.2002)}

O VI Laudo Arbitral foi concluído na controvérsia surgida da reclamação do Uruguai contra a proibição brasileira (pela Portaria n ${ }^{\circ} 8 / 00$ da Secretaria de Comércio Exterior do Ministério do Desenvolvimento, Indústria e Comércio Exterior - SECEX) da importação de pneumáticos recauchutados e usados.

Para o Uruguai, a proibição imposta a pneumáticos recauchutados estendia aquela já existente para produtos usados, configurando uma restrição injustificada ao comércio regional. Em resposta, o Brasil sustentou o caráter meramente interpretativo da cláusula que abrangeu expressamente os produtos remoldados, já inclúdos na legislação anterior entre os usados, porém não de forma explícita, o que levava indevidamente à não-observância da restrição para os remoldados.

O Brasil não invocou a proteção ambiental como fundamento para a alteração da legislação sobre importação de pneumáticos recondicionados. A única questão relacionada com o ambiente que veio à luz no VI Laudo Arbitral foi a Resolução n ${ }^{\circ}$ 258/99 do CONAMA, órgão ambiental brasileiro. Para o Uruguai, essa resolução permitia a importação, além de pneus usados, de pneus provenientes de várias formas de recondicionamento. $\mathrm{O}$ Brasil contestou esse argumento dizendo que o CONAMA sequer teria competência para atuar no comércio, destinando-se a dita resolução apenas à proteção ambiental, determinando a finalização adequada de pneus inservíveis, não importanto a forma como tivessem entrado no país; esta, a entrada dos pneus no país, seria regulada pelos órgãos de comércio.

A decisão do Tribunal foi pela procedência da reclamação do Uruguai, devendo o Brasil adequar sua legislação interna de maneira a permitir a importação de pneus remoldados originários dos países do bloco.

Observa-se, portanto, que a controvérsia, no âmbito do Mercosul, resolveu-se pelo viés do comércio, e não da proteção ambiental. Entretanto, é válido mencionar que a nova legislação brasileira, destinada a acatar a decisão do Tribunal ad hoc emissor do VI Laudo Arbitral (Portaria SECEX $n^{\circ} 2 / 02$ e Decreto $n^{\circ} 4.592 / 03$, que alterou o Decreto $n^{\circ}$ $3.179 / 99$ ), foi objeto de discussão nos tribunais internos, agora pelo viés ambiental.

Na Ação Civil Pública n 2003.71.00.033004-2 ( $6^{\mathrm{a}}$ Vara Federal de Porto Alegre), por exemplo, o Ministério Público asseverou que a permissão de importação dos pneus recauchutados ia contra o princípio da precaução, por não haver estudo de impacto ambiental sobre os riscos ambientais desses produtos. O MP recordou a vedação, contida no Tratado de Montevidéu (1980), de medida de ordem econômica incompatível com a proteção da saúde humana e do meio ambiente. Já na decisão sobre o pedido de liminar, a júzza entendeu por bem evitar o prejuízo à integração no Mercosul que a cassação do novo regramento poderia representar. A decisão foi confirmada pelo Tribunal Regional Federal da $4^{2}$ Região. 
No Mandado de Segurança n ${ }^{\circ} 2003.5101020151-7$ (24 Vara Federal do Rio de Janeiro), uma empresa atacava $\mathrm{o}$ ato da autoridade de comércio exterior consistente na nãoemissão de licenças para importação de pneus recauchutados. Tanto o juiz de primeira instância quanto o Tribunal Regional Federal da $2^{a}$ Região e o Superior Tribunal de Justiça deram razão à empresa, considerando o Decreto $n^{\circ} 4.592 / 03$ e o VI Laudo Arbitral do Mercosul, bem como o preenchimento, pela impetrante, da exigência da Resolução n ${ }^{\circ}$ 258/ 99 do CONAMA (dar finalização ambientalmente adequada a pneus inservíveis para importar quantidade proporcional de pneus remoldados).

Vale dizer, no caso dos pneus remoldados, no âmbito do Mercosul, perante o Tribunal ad hoc, a precaução sequer entrou em pauta. Já no judiciário brasileiro, a precaução foi ventilada, porém não encontrou respaldo. Não se pode deixar de reconhecer, entretanto, que a simples permissão de importação de pneus recauchutados, por si só, não representa um risco ambiental. Os possíveis impactos dependem do finalização que se der aos produtos, e os pneus novos, depois de usados, não estão a salvo de produzirem os mesmos impactos.

\section{Laudo Arbitral - Obstáculos à entrada de produtos fitossanitários argentinos no mercado brasileiro (19.04.2002)}

O VII Laudo Arbitral do Mercosul foi produzido pelo Tribunal ad hoc instaurado para apreciar a reclamação da Argentina contra o Brasil, por não ter este último incorporado uma série de decisões do Mercosul tendentes a harmonizar as legislações dos EstadosMembros sobre produtos fitossanitátios (Resoluções GMC n ${ }^{\circ}$ 48/96, 87/96, 149/96, 156/ 96 e $71 / 98$ ). A omissão do Brasil estaria impedindo a vigência da normativa Mercosul, que depende da internalização por todos os Membros. Conseqüentemente, restringia a entrada de produtos argentinos no país.

Com efeito, a legislação brasileiro subordina a produção, a comercialização e o consumo de agrotóxicos à sua compatibilidade comn diretivas das autoridades da saúde, do ambiente e da agricultura (Lei $n^{\circ} 7.802 / 89$, art. $3^{\circ}$ ). Além disso, o registro de novos produtos só deve ser permitido se seus efeitos tóxicos sobre a saúde humana e o meio ambiente forem comprovadamente iguais ou menores que os dos produtos já existentes (Decreto $n^{\circ} 4.074$ / 02, art. 20); outra exigência é que o Brasil disponha de métodos para desativação dos componentes do agrotóxico, de modo a evitar que os resíduos ponham em risco a saúde ou o ambiente (Lei ${ }^{\circ} 7.802 / 89$, art. $\left.3^{\circ}, \$ 6^{\circ}\right)$.

Em resposta à reclamação da Argentina, o Brasil sustentou que a obrigação de incorporar a normativa Mercosul não tinha prazo para concretizar-se, na ausência de uma disposição assim nos Tratados. O Tribunal acabou rejeitando esse argumento ao entender que, apesar da inexistência de uma data limite, a incorporação deveria ocorrer num prazo razoável, lapso já ultrapassado pela omissão brasileira.

O Brasil também lembrou que, pelo seu art. $1^{\circ}$, o Tratado de Assunção não veda a adoção de medidas unilateriais para a realização de objetivos de políticas públicas de proteção da saúde, do meio ambiente e da segurança da população, e a legislação brasileira sobre 
fitossanitários, embora apontada como restritiva pela Argentina, não era discriminatória, pois aplicada tanto aos produtos nacionais quanto aos importados. $\mathrm{Na}$ mesma linha, lembrou-se que o art. 50 do Tratado de Montevidéu de 1980, do qual fazem parte os dois Estados implicados, previa que as disposições ali contidas não deveriam obstar à adoção de medidas destinadas à "proteção da vida e da saúde das pessoas, animais e vegetais" (itern "d"), entre outros.

A propósito de normas ambientais e de sua harmonização no Mercosul, vale mencionar a sugestão de Aurélio Virgílio Veiga Rios de adoção do critério mais rígido possível, pois tanto um nivelamento pelo mínimo quanto pela média seriam indesejáveis, considerando que o Brasil tem a legislação mais avançada nesse campo. ${ }^{10}$ Realmente, o nivelamento pelo mínimo representaria um retrocesso para os Estados-Partes dotados de legislação mais desenvolvida; a exigência de um padrão pela média teria o mesmo problema, e acrescentaria a dificuldade de os Estados com legislação menos protetiva para se ajustarem. Então, sendo necessária, de qualquer forma, a provação desse ajustamento, mais vale adotar o critério mais elevado.

Contudo, o fato é que o Tribunal entendeu que a invocação genérica da possibilidade de produtos fitossanitários causarem dano à saúde não era suficiente para restringir sua comercialização. Afinal, o Brasil não teria feito prova dessa potencialidade danosa (vale dizer, o Tribunal atribuiu ao Brasil o onus probandi). O Tribunal admitiu que, num caso concreto, verificada a possibilidade de um determinado produto prejudicar a saúde ou a vida humana, animal ou vegetal, poderia ser restringido esse produto, mas não toda a categoria de fitossanitários.

A lição a tirar desses dois casos do Mercosul é a de que a precaução foi mal empregada ali, pois, no máximo, foram feitas alegações genéricas de que os produtos objetos das controvérsias poderiarn causar dano à saúde. Não havia prova alguma de uma possibilidade mais concreta de um ou outro produto determinado terem efeitos negativos do ponto de vista da saúde humana e do ambiente. É verdade que o princípio da precaução determina, entre outros, a inversão do ônus da prova. ${ }^{11}$ Porém, faz-se necessário algum indicativo dos efeitos nefastos de um produto que se queira restringir, ou, a se admitir aquelas alegações mais vagas, nenhuma tecnologia ou produto novo teria aval para ser desenvolvido, pois não há como prever todos os seus efeitos ambientais futuros.

${ }^{10}$ RIOS, Aurélio Virgílio Veiga. O Mercosul, os agrotóxicos e princípio da precaução, In: Revista de Direito Difusos, vol. 13, junho/2002, p. 1682-1683.

${ }^{11}$ RIOS, op. cit., p. 1685. 


\section{CONCLUSÕES}

É possível identificar, na aplicação do princípio da precaução, uma concepção forte e uma concepção fraca. ${ }^{12} \mathrm{~A}$ forte exige, para a liberação de uma atividade, produto ou tecnologia, certeza de que não produzirá efeitos (nocivos) além dos esperados. ${ }^{13}$ Mas essa tendência não deve ser exagerada, pois uma interpretação literal do dispositivo da Carta Munidal sobre a Natureza de 1982, segundo o qual "sempre que efeitos potenciais adversos não forem plenamente conhecidos, as atividades não podem ocorrer", conduziria a que nenhuma nova tecnologia, atividade ou produto atende à precaução. ${ }^{14}$

A fraca, na avaliação da oportunidade de uma tecnologia ou da instalação de um empreendimento, leva em conta os riscos, os custos, os benefícios, numa perspectiva antropocêntrica (não ecocêntrica) moderada ("responsável"), ou seja, estende a (im)previsibilidade de impacto ambiental até limites razoáveis, temperados, entre outros, pelo retorno social esperado. ${ }^{15}$

Haveria, ainda, de um ângulo mais pessimista, uma concepção "fraquíssima": a precaução seria uma recomendação não vinculante para os Estados, permitindo um enfoque mais permissivo do uso dos recursos naturais, priorizando o "desenvolvimento" sobre a conservação ambiental, qualidade de vida, preservação da biodiversidade etc. Esse ponto de vista também assume esta terceira concepção como a que tem sido a mais adotada na prática internacional. $^{16}$

De fato, o que se tem visto na prática internacional quanto à precaução é, acima de tudo, uma hesitação em aplicá-la por não se ter certeza de que ela se tenha cristalizado no direito costumeiro internacional. Por isso, na dúvida sobre esse ponto, e sendo a precaução inconciliável com outras regras de direito internacional em casos concretos, é comum preterila em favor de regras já tradicionais. Do ponto estritamente técnico, parece acertada essa posição. O problema é que, se não se dá trânsito à precaução, e às normas de direito internacional ambiental em geral, colocando-as em prática, jamais elas poderão disputar uma hierarquia superior a outras normas internacionais.

Contudo, os casos analisados permitem entrever diferentes aproximações ao princípio da precaução. A decisão da Corte Internacional de Justiça no caso Gabcíkovo-

${ }^{12}$ SAMPAIO, José Adércio Leite. Constituição e meio ambiente na perspectiva do direito constitucional comparado. In: Princípios de Direito Ambiental na dimensão internacional e comparada. Belo Horizonte, Del Rey, 2003. p. 59.

${ }^{13}$ SAMPAIO, op. cit., p. 60; TINKER, Catherine. State responsibility and the precautionary principle. In: FREESTONE, David e HEY, Ellen (eds.). The Precautionary Principle and International Law - The challenge of implementation. The Hague, London, Boston: Kluwer Law International, 1996. p. 56.

${ }^{14}$ SAMPAIO, op. cit., p. 60.

${ }^{15}$ SAMPAIO, op. cit., p. 62.

${ }^{16}$ TINKER, op. cit., p. 56-57. 
Nagymaros, entre Hungria e Eslováquia, parece ter sido bem simplificadora: apesar de ter plena ciência dos riscos ambientais envolvidos, a Corte preferiu sustentar a primazia da máxima pacta sunt servanda em direito internacional, passando por cima dos recentes desenvolvimentos do direito internacional ambiental, inclusive com desprezo da constatação de que os custos de reparação dos prejuízos ambientais seriam mais elevados que os de prevenção.

Já no caso do Mercosul sobre pneumáticos, como visto, a questão da precaução não foi questionada no seio do Tribunal ad hoc, senão apenas nos tribunais internos brasileiros. Por outro lado, no caso dos produtos fitossanitários, foi invocada a necessidade de proteger, em nome da precaução, a saúde humana e o meio ambiente. Nos dois casos, contudo, não houve maior preocupação dos interessados em comprovar que os riscos alegados poderiam realmente materializar-se. Assim, os tribunais internos e o Tribunal ad hoc não tiveram maiores dificuldades em descartar a justificativa da precaução. Afinal, ela não requer uma demonstração absoluta da atualidade dos riscos, mas, ao menos, indicativos sérios de sua possibilidade.

Quer dizer, nesses casos, não foi o órgão jurisdicional que promoveu um potencial prejuizo ao ambiente, desconsiderando indevidamente o argumento da precaução, senão as partes nas controvérsias, que não o manusearam como desejável (Brasil no âmbito do Mercosul, Ministério Público nos tribunais internos). Na verdade, no caso dos fitossanitários, o Tribunal não pôde senão reconhecer a atitude brasileira como restritiva do comércio regional. Os princípios da precaução e da prevenção devem orientar o registro e o licenciamento ambiental de produtos como os agrotóxicos, ${ }^{17}$ por exemplo, mas cumpriria ao Brasil, no âmbito da precaução mesma, empreender ou aprofundar as pesquisas sobre os efeitos negativos dos produtos sobre que havia essa dúvida para justificar seu banimento.

Por seu turno, a Organização Mundial do Comércio teve de enfrentar argumentos sétios em favor da proteção da saúde e da vida humana, animal e vegetal, e adotou uma posição compatível com os fins para que foi criada, vale dizer, a liberalização do comércio mundial. No caso dos padrões para gasolina reformulada e convencional, pode-se dizer que houve uma falha dos Estados Unidos ao discriminar o produto importado em benefício do nacional. Talvez a recomendação seja de que os exportadores também pudessem usar os critérios mais benéficos (apesar das dificuldades aí implicadas para a determinação da qualidade de seu produto), pois o beneficiado seria o ambiente se não tivesse havido meio de contestar a lei da gasolina americana.

Ainda no âmbito da OMC, o caso Hormônios foi resolvido com uma argumentação na mesma linha do anterior, em princípio coerente com os fins e objetivos da Organização. No entanto, é forçoso reconhecer que, nesse caso, a precaução foi aventada com base no

${ }^{17}$ RIOS, op. cit., p. 1691. 
próprio SPS Agreement. Além de autorizar medidas sanitárias e fitossanitárias dentro das mesmas balizas do GATT, o Acordo vai mais adiante, permitindo a adoção de medidas mesmo sem a comprovação científica dos riscos que se pretende evitar, embora temporariamente. Ora, como exceção, essa regra não deveria ser bloqueada pela própria regra geral, como foi o caso.

Finalmente, no caso Bluefin Tuna, o Tribunal Internacional para o Direito do Mar outorgou medidas provisionais com uma percepção ponderada da precaução, determinando a cessação do programa japonês que implicava o aumento de sua quota de pescado, com possível prejuízo para a biomassa. Ao mesmo tempo, recomendou o aprofundamento de estudos sobre a espécie de atum em questão, com a ressalva de que, até que se alcançassem dados conclusivos, não se aumentasse a quantidade total permitida de pesca, garantindo a preservação do atum nos níveis populacionais em que se encontrava até ali.

Esta última decisão indica uma mudança positiva na concepção da precaução e das normas de direito internacional ambiental. Espera-se que constitua verdadeiramente um marco para as próximas decisões, em âmbito global, sobre problemas relacionados à preservação do ambiente e da saúde humana. No entanto, fica a lição do caso sobre produtos fitossanitários no Mercosul: apenas alegar genericamente a necessidade de precaução não contribui para o desenvolvimento da proteção ambiental. 